\title{
Brain Error-Monitoring Activity is Affected by Semantic Relatedness: An Event-related Brain Potentials Study
}

\author{
Lesya Y. Ganushchak ${ }^{1}$ and Niels O. Schiller ${ }^{1,2}$
}

\begin{abstract}
Speakers continuously monitor what they say. Sometimes, self-monitoring malfunctions and errors pass undetected and uncorrected. In the field of action monitoring, an event-related brain potential, the error-related negativity (ERN), is associated with error processing. The present study relates the ERN to verbal self-monitoring and investigates how the ERN is affected by auditory distractors during verbal monitoring. We found that the ERN was largest following errors that occurred after semantically
\end{abstract}

related distractors had been presented, as compared to semantically unrelated ones. This result demonstrates that the ERN is sensitive not only to response conflict resulting from the incompatibility of motor responses but also to more abstract lexical retrieval conflict resulting from activation of multiple lexical entries. This, in turn, suggests that the functioning of the verbal self-monitoring system during speaking is comparable to other performance monitoring, such as action monitoring.

\section{INTRODUCTION}

The neural basis of error monitoring has become a key issue in cognitive neuroscience. An electrophysiological index thought to be associated with error processing is the error-related negativity (ERN; Gehring, Goss, Coles, Meyer, \& Donchin, 1993; Falkenstein, Hohnsbein, Hoorman, \& Blanke, 1991). The ERN is an event-related potential (ERP) that has a fronto-central scalp distribution and peaks about $80 \mathrm{msec}$ after an overt incorrect response (Holroyd \& Yeung, 2003; Scheffers, Coles, Bernstein, Gehring, \& Donchin, 1996; Bernstein, Scheffers, \& Coles, 1995). Originally, the ERN was thought to arise as a result of conscious error detection (Bernstein et al., 1995). This hypothesis assumes a comparison between the internal representation of the intended correct response, arising from ongoing stimulus processing, and the internal representation of the actual response, resulting from the efferent copy of the motor activity. If there is a mismatch between these two representations, then an ERN will be generated (Holroyd \& Coles, 2002; Falkenstein, Hoormann, Christ, \& Hohnsbein, 2000; Bernstein et al., 1995).

This view has been challenged by the conflict hypothesis. According to this view, the ERN reflects detection of response conflict and not detection of errors per se (Botvinick, Braver, Barch, Carter, \& Cohen, 2001; Carter et al., 1998). Response conflict arises when multiple re-

\footnotetext{
${ }^{1}$ Leiden Institute for Brain and Cognition, The Netherlands,

${ }^{2}$ Maastricht University, The Netherlands
}

sponses compete for selection. Presence of conflicting responses reflects situations where errors are likely to occur. Thus, according to the conflict hypothesis, error detection is not an independent process but based on the presence of response conflict.

Alternatively, the reinforcement learning theory proposed that the ERN may reflect a negative rewardprediction error signal that is elicited when the monitor detects that the consequences of an action are worse than expected. This reward-prediction error signal is coded by the mesencephalic dopamine system and projected to the anterior cingulate cortex (ACC), where the ERN is elicited (Holroyd \& Coles, 2002).

A large set of studies on the ERN investigated the functioning of action monitoring. In the present study, we focused on a different type of monitoring, namely, verbal self-monitoring. Verbal self-monitoring is a crucial part of language production, especially when one considers that producing speech errors hampers the fluency of speech and can sometimes lead to embarrassment, for instance, when taboo words are uttered unintentionally (Motley, Camden, \& Baars, 1982). Furthermore, malfunction of verbal monitoring is often implicated in disorders such as aphasia (for an overview, see Oomen, Postma, \& Kolk, 2001), stuttering (Lickley, Hartsuiker, Corley, Russell, \& Nelson, 2005), and schizophrenia (for an overview, see Seal, Aleman, \& McGuire, 2004).

One prominent theory about verbal self-monitoring is the perceptual loop theory proposed by Levelt (1983, 1989). According to this theory, a speech monitor checks the message for its appropriateness, inspects the speech 
plan, and detects errors prior to its articulation (Schiller, 2005, 2006; Schiller, Jansma, Peters, \& Levelt, 2006; Wheeldon \& Morgan, 2002; Postma \& Noordanus, 1996; Wheeldon \& Levelt, 1995), as well as after the speech has become overt (Postma, 2000). Verbal self-monitoring is achieved via the speech comprehension system, that is, the same system that is used for understanding the speech of others. The precise working of the monitor is not described in detail by theories of language production (e.g., Levelt, Roelofs, \& Meyer, 1999 for an overview). However, the system must consist of at least two components, one of which attends to the output of the speech programming process, and another one that compares this output with some standard. If the output does not satisfy a particular criterion, the monitor initiates a selfcorrection process (Postma, 2000; Levelt et al., 1999).

A similar mechanism is implemented in a model of action monitoring (Desmurget \& Grafton, 2000). According to this model, the action monitor is a feed-forward control mechanism that is used to inhibit and correct a faulty response (Rodrígues-Fornells, Kurzbuch, \& Münte, 2002; Desmurget \& Grafton, 2000). When the wrong selection of the motor command is generated, a copy of an on-line response is produced and compared to the representation of the correct response. If there is a mismatch between the copy of the on-line response and the representation of the correct response, an error signal is generated and a stop command is initiated (Coles, Scheffers, \& Holroyd, 2001).

The central question we try to answer in this study is: Does verbal monitoring work in a similar way as action monitoring? It seems plausible that different types of monitoring have the same key mechanisms to monitor different kinds of behavioral output. An action monitor, for example, may monitor for motor slips by checking for possible mismatches between representations of actual and desired motor behavior. A verbal monitor, on the other hand, may monitor some internal representation as it is generated during speech planning by checking potential mismatches between intended and actual verbal production.

If the ERN is associated with error processing in action monitoring, can it also be applied to error processing in verbal monitoring? Previous studies showed that an ERN can be elicited by verbal errors (e.g., Ganushchak \& Schiller, 2006; Sebastián-Gallés, Rodríguez-Fornells, De Diego-Balaquer, \& Díaz, 2006; Masaki, Tanaka, Takasawa, \& Yamazaki, 2001). For instance, Masaki et al. (2001) examined whether the ERN occurs in relation to speech errors in the Stroop color-word task. Participants were instructed to overtly name the color of each stimulus. Masaki and colleagues found a negative deflection of the ERP signal followed by a positive one shortly after incorrect responses with the same polarity, latency, and scalp distribution as the typical ERN found in motor tasks. Therefore, these authors concluded that ERN-like components can also be found after vocal slips.
Ganushchak and Schiller (2006) used a phoneme monitoring task to address the question whether an ERN occurs after verbal error detection and whether a potential ERN is affected by a time pressure manipulation. These authors obtained an ERN following verbal errors. Furthermore, their ERN showed a decrease in amplitude under conditions of severe time pressure.

Recently, Möller, Jansma, Rodríguez-Fornells, and Münte (2007) used a laboratory task known to elicit speech errors. In this task, participants are presented with inductor word pairs such as ball doze, bash door, and bean deck, which are followed by a target word pair such as darn bore (Motley et al., 1982). The reversal of initial phonemes in the target pair compared to the inductor pairs is supposed to lead to speech errors (e.g., barn door). Möller et al. (2007) asked their participants to covertly read the inductor word pairs and vocalize the target word pair immediately preceding a response cue. Möller et al. found a negative deflection on error trials, as compared to correct trials, preceding the response cue. They proposed that this activity reflects the simultaneous activation of competing speech plans. However, the authors do not make an explicit link between the negativity they found in their study and the ERN.

\section{Current Study}

The task employed in our present study was a phoneme monitoring go/no-go task, previously used in language production and verbal monitoring research (e.g., Schiller, 2005; Morgan \& Wheeldon, 2003; Wheeldon \& Levelt, 1995). In the current study, participants were required to internally name pictures and press a button if a particular target phoneme occurred in the name of the picture. For instance, if the target phoneme was $/ \mathrm{b} /$ and the target picture was bear, participants were required to press a response button. Thus, participants were asked to monitor their own internal speech production. Target pictures were presented with or without auditory distractors (stimulus onset asynchrony $[\mathrm{SOA}]=0 \mathrm{msec}$ ), which were semantically related or unrelated to the target pictures.

Previous studies have shown that participants are slower in naming pictures when distractors are semantically related to target pictures than when they are unrelated (e.g., Damian \& Martin, 1999; Starreveld \& La Heij, 1995, 1996; Schriefers, Meyer, \& Levelt, 1990; Lupker, 1979). Current models of word production have proposed various accounts for this semantic interference effect (e.g., Levelt et al., 1999; Schriefers et al., 1990), but they share the core assumption that semantically related concepts, such as train and bus, coactivate each other through activation spreading in a semantic network (Collins \& Loftus, 1975; Quillian, 1968). Coactivated concepts activate their corresponding lexical entries which compete for selection, and this competition affects selection latencies (see Levelt et al., 1999 for a review; but see Mahon, Costa, Peterson, Vargas, \& Caramazza, 2007; Finkbeiner, Gollan, 
\& Caramazza, 2006 for an alternative view). The concept with the highest activation is selected for further processing. In light of these findings, we expected that, in the present study, semantically related distractors, as opposed to semantically unrelated distractors, would cause more lexical retrieval conflict, thereby leading to slower and more error-prone functioning of the monitor (Damian \& Martin, 1999; Schriefers et al., 1990; Lupker, 1979).

Moreover, the perceptual loop theory (Levelt, 1983, 1989) assumes that verbal self-monitoring occurs through the speech comprehension system. Thus, we expected that auditory distractors will cause longer button press latencies and higher error rates by impeding the functioning of the verbal self-monitor, compared to performance in the absence of the distractors.

Beside behavioral effects, we explored two ERP components in relation to verbal monitoring: the ERN and the N450. The N450 reflects negativity over fronto-central regions that peaks about $450 \mathrm{msec}$ after stimulus onset on correct trials (West, 2003; Liotti, Woldorff, Perez, \& Mayberg, 2000). The N450 is associated with lexical conflict in studies employing a Stroop task and is elicited by both response and nonresponse conflict (i.e., conflict that arises prior to response processing, e.g., at phonetic and/ or semantic levels; West, Bowry, \& McConville, 2004; Liotti et al., 2000). The amplitude of the N450 is larger when color and word information are incongruent than when they are congruent (West, 2003). In the present study, we expected to find an increase in the amplitude of the $\mathrm{N} 450$ in the presence of semantically related distractors because they will cause higher lexical conflict than semantically unrelated distractors. The N450 amplitude should be smallest in the control condition (i.e., in the absence of distractors) because, in the control condition, there should be little conflict present. Note that West (2003) showed higher amplitudes of the N450 on incongruent trials, whereas we expected to find higher amplitudes of the N450 on congruent (i.e., semantically related) trials. This seeming contradiction is resolved when one considers the amount of conflict at the aforementioned trials. In a Stroop task, incongruent trials (e.g., the word RED presented in blue) lead to more conflict than congruent trials (e.g., RED presented in red). In our study, in contrast, congruent trials (e.g., a picture of a nose presented with word EAR) yield more conflict than incongruent trials (e.g., picture of a nose presented with word WINDOW).

Additionally, in response-locked electroencephalographic (EEG) averages, the ERN was of special interest to us. Throughout the action monitoring literature, it has consistently been reported that the amplitude of the ERN increases when response conflict was increased (e.g., Yeung, Botvinick, \& Cohen, 2004). However, there are no studies showing that the ERN can be affected by lexical retrieval conflict. As mentioned above, the presence of the semantically related distractors as compared to semantically unrelated ones may activate more entries that compete for response selection. For example, see- ing a picture of a nose and hearing the distractor word ear will also activate other entries from the same semantic category, such as lip, tongue, eye, and so forth, thereby increasing the number of possibly correct (i.e., more or less appropriate) responses. This, in turn, may lead to increased response conflict and higher amplitudes of the ERN. Sensitivity of the ERN to the increase of lexical conflict might provide extra evidence for the hypothesis that verbal monitoring involves similar processes as nonverbal action monitoring. We expected to find no difference in the latency of the ERN because latency seems to be invariant to the erroneous responses and largely independent from experimental manipulation (Falkenstein et al., 2000; Scheffers \& Coles, 2000).

To summarize, we hypothesized that auditory distractors, by impeding the functioning of the verbal monitor and by increasing lexical conflict, lead to slower and more erroneous responses, as well as larger amplitudes of the ERN and the N450.

\section{METHODS}

\section{Participants}

Twenty-two students of Maastricht University (19 women) took part in the experiment. All participants were righthanded, native speakers of Dutch, and had normal or corrected-to-normal vision. Participants gave written informed consent prior to participating in the study. They received a small financial reward for their participation in the experiment. Two participants were excluded from the analysis because they made no errors, which made it impossible to compute an ERN.

\section{Materials}

Forty simple line drawings were used as target pictures in this experiment. The labels of all the pictures were monosyllabic Dutch words (e.g., beks "witch," brood "bread," etc.). All picture names had a moderate frequency of occurrence between 10 and 100 per million according to the CELEX database (see Table 1; CEnter for LEXical information, Nijmegen; Baayen, Piepenbrock, \& Gulikers, 1995). Labels of the pictures started with consonants. The position of the target phoneme was equated across the stimuli.

For each picture, a word from the same semantic category was selected that served as semantically related distractor (e.g., for the target picture neus "nose" the semantically related distractor was OOR "ear"). An unrelated word without any obvious relationship to the target picture served as semantically unrelated distractor (e.g., the target picture neus "nose" was paired with the word RAAM "window"). Semantically related and unrelated distractors were selected such that they were phonologically unrelated to the picture labels. Target phonemes, for which participants were required to monitor during the task, were not contained in the distractors. 
Table 1. Lexico-statistical Characteristics of the Target Words

\begin{tabular}{llcc}
\hline $\begin{array}{l}\text { Target } \\
\text { Phoneme }\end{array}$ & Example & $\begin{array}{c}\text { Mean CELEX } \\
\text { Frequency (per } \\
\text { one million words) }\end{array}$ & $\begin{array}{c}\text { Mean } \\
\text { Length in } \\
\text { Segments }\end{array}$ \\
\hline /t/ & troon ("throne") & 23.2 & 4.5 \\
/k/ & kraan ("faucet") & 28.4 & 4.2 \\
/p/ & paard ("horse") & 33.1 & 4.1 \\
/n/ & naald ("needle") & 30.6 & 4.2 \\
/m/ & maan ("moon") & 33.3 & 4.0 \\
/l/ & lamp ("lamp") & 33.5 & 4.6 \\
/s/ & schoen ("shoe") & 31.9 & 4.5 \\
/r/ & riem ("belt") & 29.9 & 4.3 \\
\hline
\end{tabular}

Due to the difficulty of finding distractors which did not contain target phonemes, pictures for go and no-go trials were paired with different distractors. Distractors that were semantically related during go trials were used as semantically unrelated ones during the no-go trials and vice versa. For instance, on go trials, the target picture neus "nose" was paired with the semantically related distractor OOR "ear"; on no-go trials, this distractor was paired as semantically unrelated distractor with the picture fles "bottle" (see the Appendix for the list of pictures and distractors). Distractor words for a particular target were matched for frequency of occurrence, number of syllables, and number of letters.

\section{Design}

The experiment consisted of three experimental conditions: a control condition (CC), an auditory interfer- ence condition with semantically related distractors $(\mathrm{SR}+)$, and an auditory interference condition with semantically unrelated distractors (SR-). During the CC trials, participants only saw pictures, whereas during auditory interference conditions ( $\mathrm{SR}+$ and $\mathrm{SR}-$ ), pictures were presented simultaneously with auditory distractors $(\mathrm{SOA}=0 \mathrm{msec})$. Some of the $\mathrm{SR}+$ and $\mathrm{SR}-$ trials $(8.5 \%$ of all trials) were catch trials during which participants were asked to overtly name the last distractor word they heard.

There were 20 experimental blocks of, on average, 24 trials and 1 practice block of 19 trials. In each block, participants were asked to monitor for a different target phoneme. The target phonemes were: $/ \mathrm{t} /, / \mathrm{k} /, / \mathrm{p} /, / \mathrm{n} /$, $/ \mathrm{m} /, / \mathrm{l} /, / \mathrm{s} /$, and $/ \mathrm{r} /$; the phoneme $/ \mathrm{b} /$ was used in practice trials. In all blocks, pictures were presented one by one on a computer screen. In each condition, each picture was repeated four times: twice as a nontarget and twice as a target. Each time, participants were asked to monitor for a different phoneme. For instance, participants were asked to monitor once for the phoneme $/ \mathrm{n} /$ and once for the phoneme /s/ when neus "nose" was a target. When neus was a nontarget, participants had to monitor for $/ \mathrm{k} /$ and $/ \mathrm{r}$ / (see Figure 1 for an illustration of the task). A fixation point always preceded the pictures. The duration of the fixation point varied between 500 and $800 \mathrm{msec}$. In all conditions and after each trial, participants rated the accuracy of their response on a 3-point Likert scale. The Likert scale was presented in the middle of the screen after a fixed time interval of 1000 msec following disappearance of the visual stimulus or after a response to the target picture has been made. This scale included the following options: surely correct, do not know, and surely incorrect. Order of pictures was pseudorandomized such that the same
Figure 1. Example of the go and no-go trials for three auditory conditions, namely, control condition (CC), semantically related distractors $(\mathrm{SR}+)$, and semantically unrelated distractors (SR-). In the figure, Dutch picture names written in phonetic transcription (taken from the CELEX database) and English translations are provided in brackets. Each picture depicted here represents separate trials. At the beginning of each block, participants heard for which phoneme they were asked to monitor.

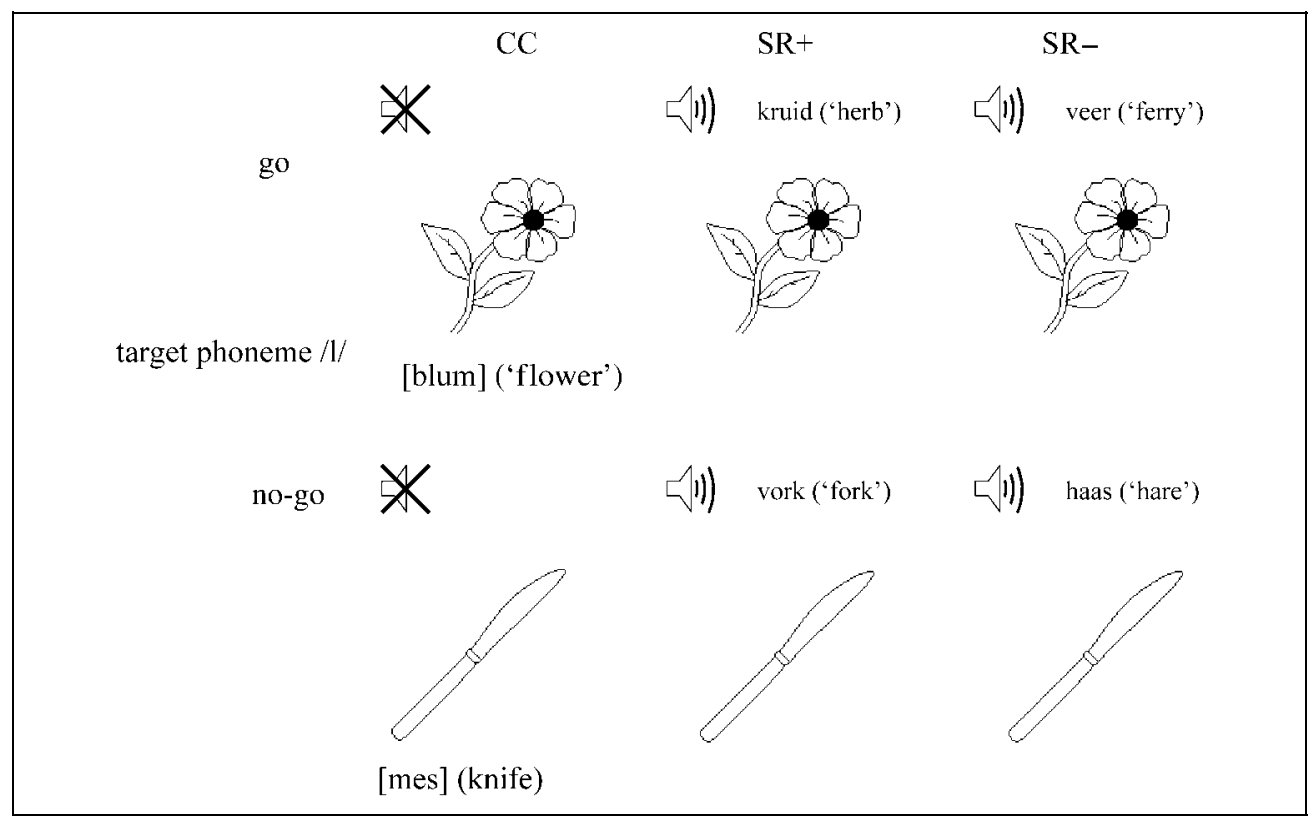


picture never appeared twice on subsequent trials. The block order was randomized for each participant.

During the learning phase, the names of the pictures were presented auditorily in order to avoid priming for letters. The picture remained in view for $3000 \mathrm{msec}$ or until the response button was pressed. In the picture naming task, the pictures disappeared from the screen as soon as the voice key was activated or after the response deadline was reached, which was $550 \mathrm{msec}$ (this response deadline is based on the outcome of a previous study; see Ganushchak \& Schiller, 2006 for details).

\section{Procedure}

Participants were tested individually while seated in a sound-proof room. They were presented with a familiarization phase, a picture naming task, a practice block, and the experimental blocks. During the familiarization phase, participants were familiarized with the pictures and their corresponding names. In the picture naming task, participants were asked to overtly name pictures with the labels they were familiarized with previously. If errors were made, participants were told about their mistakes and correct responses were provided. Prior to practice and experimental blocks, participants received an auditory sample of the phoneme they were required to detect (e.g., Reageer nu op de klank /l/ zo als in tafel, spelen, verbaal "React now to the sound $/ 1 /$ as in table, play, tale"). Participants were asked to press a button if a target phoneme was present in the picture name (i.e., go trials). When a target phoneme was not present in the name of the picture, participants were required to refrain from button pressing (i.e., no-go trials). Participants were instructed to give all responses to go trials with their right hand. Responses to the Likert scale were given with the left hand. During the catch trials, participants were asked to say out loud the last distractor word they heard. Participants were instructed to sit as still as possible and to suppress eye blinks while a picture was on the screen and during button presses.

\section{Apparatus and Recordings}

The EEG was recorded from 29 scalp sites (extended version of the 10-20 system) using tin electrodes mounted to an electro cap. The EEG signal was sampled at $250 \mathrm{~Hz}$ with band-pass filter from 0.05 to $30 \mathrm{~Hz}$. An electrode at the left mastoid was used for on-line referencing of the scalp electrodes. Off-line analysis included re-referencing of the scalp electrodes to the average activity of two electrodes placed on the left and right mastoid. Eye movements were recorded to allow off-line rejection of contaminated trials. Lateral eye movements were measured using a bipolar montage of electrodes placed on the right and left external canthus. Eye blinks and vertical eye movements were measured using bipolar montage of elec- trodes placed above and below the left eye. Impedance level for all electrodes was kept below $5 \mathrm{k} \Omega$.

\section{Data Analysis}

Epochs of $1300 \mathrm{msec}(-400 \mathrm{msec}$ to $+900 \mathrm{msec})$ were obtained including a 200-msec pre-response baseline. The EEG signal was corrected for vertical electrooculogram (EOG) artifacts, using the ocular reduction method described in Anderer, Safety, Kinsperger, and Semlitsch (1987). For the ERN, averaging was done across false alarm and miss trials. False alarm trials were compared with correct go trials and misses were compared with correct no-go trials. For false alarms, the amplitude and latency of the ERN was derived from each individual's responselocked average waveforms after filtering with a band pass, zero phase shift filter (frequency range was 1-12 Hz). The ERN was quantified by peak-to-peak measurements that were calculated to determine baseline independent amplitudes of negative deflections by subtracting the amplitude of the preceding positive peak from the negative peak of this component (Falkenstein et al., 2000). More specifically, the amplitude of the ERN was defined as the difference between the most negative peak in a window from 0 to 150 msec after the response and the most positive peak from -50 to 0 msec preceding the overt response (Falkenstein et al., 2000). The latency of the ERN was defined as a point in time when the negative peak was at its maximum. Misses were computed from stimuluslocked averages and analyzed with a mean area amplitude analysis, as it was impossible to identify the peaks on a trial-by-trial basis. Time windows of interest were derived based on the visual inspection of the grand-average waveforms with consideration of average button-press latencies in go trials. The selected time window of interest was 760$860 \mathrm{msec}$. The amplitude and latency of the ERN were recorded for each condition and type of error at electrode sites Fz, FCz, Cz, and Pz.

For the stimulus-locked analysis of correct trials, a band pass, zero phase shift filter (frequency range: 1-30 Hz) was used. Stimulus-locked averaging was done for correct go responses. The mean amplitude analysis was performed for the time window from 350 to 550 msec after stimulus onset. This time window was derived based on the visual inspection of the grand-average waveforms and previous studies employing the N450 (e.g., West, 2003).

\section{RESULTS}

\section{Behavioral Data}

Button-press latencies (RTs) shorter than 300 msec and longer than 1500 msec were excluded from the analysis. During catch trial, participants almost perfectly named the last word they heard (error rate: $0.4 \%$ ), indicating that participants processed the auditory input even though they were instructed to ignore distractors. The effect of 
the distractors on RTs was assessed by an analysis of variance (ANOVA) revealing a significant main effect of the distractor relatedness $\left[F(2,34)=33.62, \mathrm{MS}_{\mathrm{e}}=291.93\right.$, $p<.001]$. Participants were significantly slower during the SR+ $\left[743 \mathrm{msec}, S D=92 ; F(1,17)=48.99, \mathrm{MS}_{\mathrm{e}}=\right.$ 761.93, $p<.001]$ and SR $-[729 \mathrm{msec}, S D=94 ; F(1,18)=$ 25.17, $\left.\mathrm{MS}_{\mathrm{e}}=720.17, p<.001\right]$ conditions than during the CC (699 msec, $S D=84)$. The difference between the conditions SR + and $\mathrm{SR}-$ was also significant $[F(1,17)=$ $\left.12.73, \mathrm{MS}_{\mathrm{e}}=269.46, p<.01\right]$, that is, there was a semantic interference effect.

Similar analyses were repeated for the number of errors as dependent variable. Participants made, on average, $4.0 \%$ false alarms and $2.9 \%$ misses. An ANOVA revealed no effect of distractor relatedness $[F(2,34)<1]$.

Participants' awareness about the correctness of their response was assessed by a 3 (distractor relatedness) $\times 3$ (certainty level) ANOVA. The analysis showed a significant effect of certainty level $\left[F(2,34)=21.86, \mathrm{MS}_{\mathrm{e}}=24.87\right.$, $p<.001]$. On $90 \%$ of all error trials, participants knew that they made an error, as compared to $7 \%$ of all error trials on which participants were not aware of their errors, and $3 \%$ when they were not sure whether or not they made an error [for "sure correct" vs. "sure incorrect," $F(1,17)=$ $20.81, \mathrm{MS}_{\mathrm{e}}=24.78, p<.001$; for "do not know" vs. "sure incorrect," $F(1,17)=23.27, \mathrm{MS}_{\mathrm{e}}=24.51, p<.001$; and for "sure correct" vs. "do not know," $F(1,17)=3.01, \mathrm{MS}_{\mathrm{e}}=$ $0.46, n s]$. Neither the effect of distractor relatedness nor the interaction between distractor relatedness and certainty level was significant (both $F \mathrm{~S}<1$, respectively).

\section{Electrophysiological Data}

\section{Error-related Negativity}

The ERN was revealed in response-locked ERP averages for incorrect no-go trials (i.e., false alarms). No negative deflection was observed in the ERP waveforms for correct trials during visual inspection of the EEG waves. Unfortunately, due to the very low amount of incorrect trials during which participants were unaware of their errors (on average, there were 0.2 errors during which participants were not aware of the incorrectness of their responses), it was not possible to analyze the subjective reliability data in relation to the ERN.

Figure 2 provides an overview of the response-locked averaged ERP waveforms for false alarms (incorrect no-go

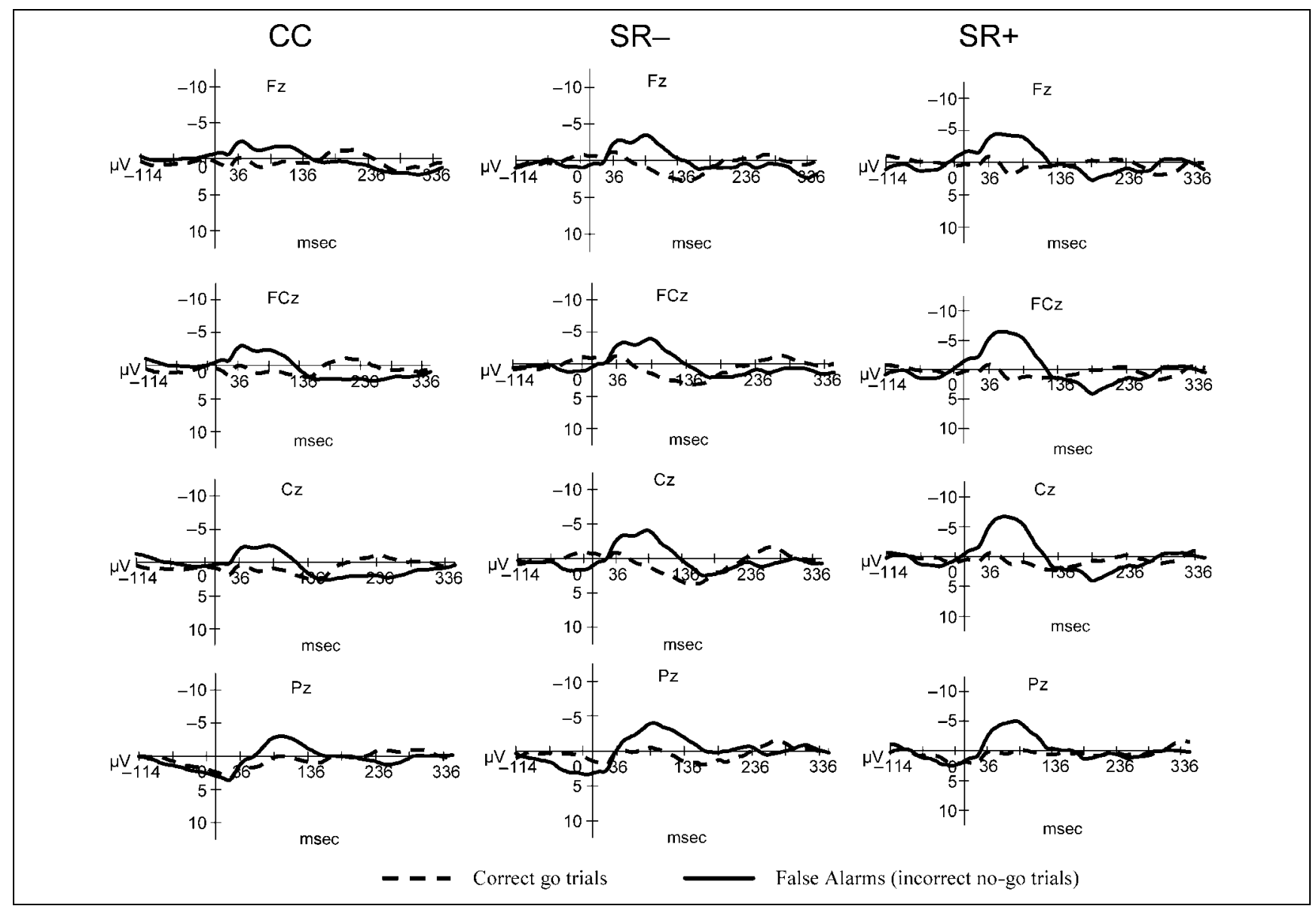

Figure 2. Averaged response-locked ERP waveforms for all false alarms (incorrect no-go trials; solid lines) versus correct trials (dashed lines) across conditions (control condition $[\mathrm{CC}]$, semantically related $[\mathrm{SR}+]$, and semantically unrelated $[\mathrm{SR}-]$ conditions). Correct and incorrect trials were matched on RTs and number of trials. 
trials) and correct go trials across distractor conditions (CC, SR+, and SR-). Figure 3 displays the topographical representation of the ERN.

To investigate the effects of the auditory interference on the ERN, an ANOVA was run with distractor relatedness as the independent variable and the amplitude of the ERN as the dependent variable. This analysis revealed a significant effect of distractor relatedness $[F(2$, $\left.34)=5.36, \mathrm{MS}_{\mathrm{e}}=63.44, p<.05\right]$. A mean area analysis in the time window of interest $(0-135 \mathrm{msec})$ was in accordance with our peak-to-peak analysis and revealed a significant effect of distractor relatedness $[F(2,34)=$ 9.47; $\left.\mathrm{MS}_{\mathrm{e}}=17.21, p<.01\right]$. The amplitude of the ERN was significantly larger in the SR+ condition $(-5.73 \mu \mathrm{V}$, $S D=2.85)$ than in the CC $[-3.06 \mu \mathrm{V}, S D=2.69 ; F(1$, $\left.17)=16.74, \mathrm{MS}_{\mathrm{e}}=27.74, p<.01\right]$ and in the SRconditions $\left[-3.19 \mu \mathrm{V}, S D=3.13 ; F(1,17)=13.56, \mathrm{MS}_{\mathrm{e}}=\right.$ $37.78, p<.01]$, again reflecting a semantic interference effect. The difference in amplitude of the ERN between

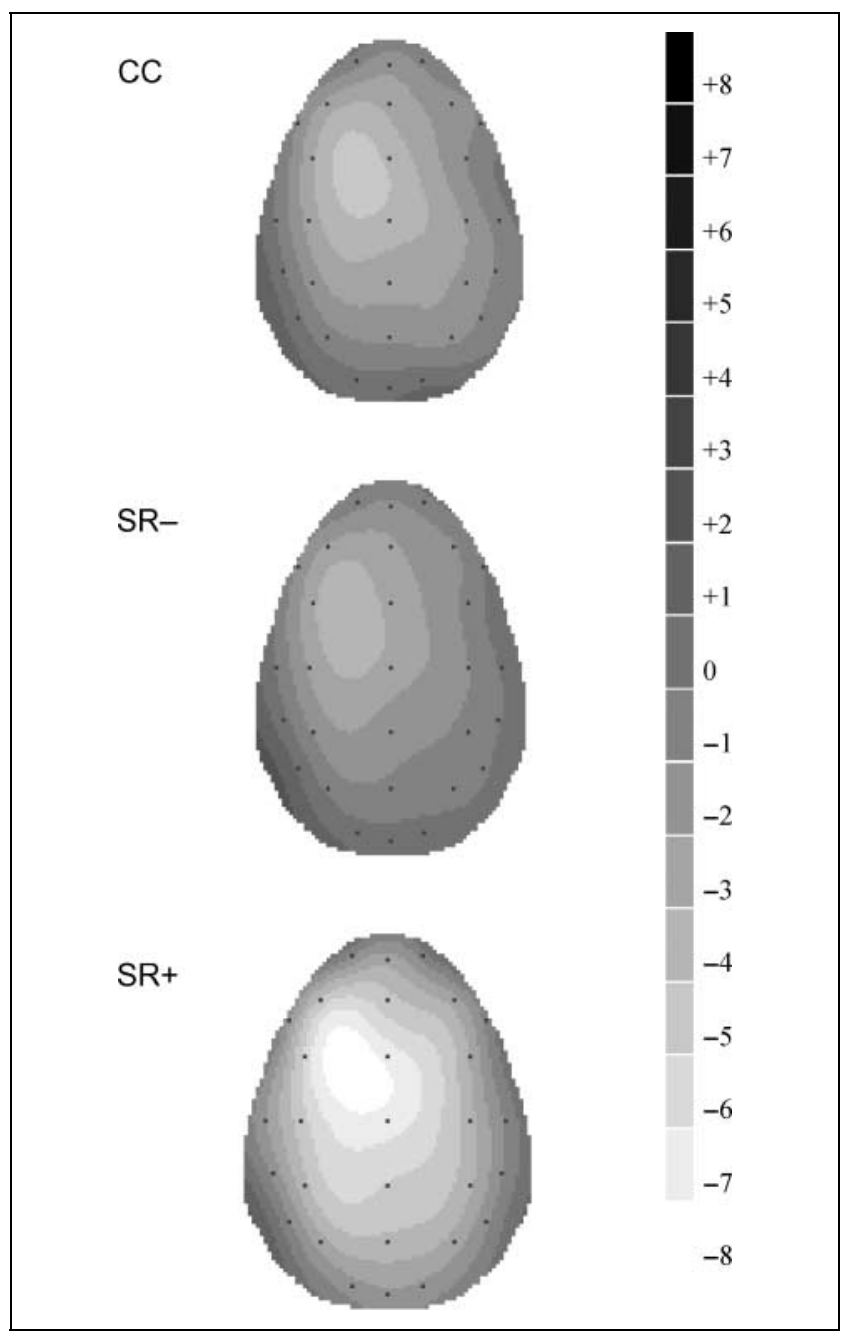

Figure 3. Topographic maps of the ERN amplitude between 0 and $120 \mathrm{msec}$ after response onset. Negative regions are depicted in light gray. the SR - condition and the CC did not reach significance $\left[F(1,17)=1.53, \mathrm{MS}_{\mathrm{e}}=37.75, n s\right]$. As expected, the analysis with the latency of the ERN as dependent variable showed no significant effect of distractor relatedness $[F(2,34)<1]$. Figure 4 displays average false alarms waveforms of all experimental conditions superimposed across four midline electrode sites.

The stimulus-locked ERP averages also showed a negative deflection for incorrect go trials (i.e., misses). This negativity was absent during correct no-go trials (i.e., correct rejections). The negative deflection observed for misses peaked approximately at the time of a potential response (see Figure 5).

A mean area analysis was used to test whether there was a significant difference between misses and correct rejections. An ANOVA was run with correctness of response as the independent variable and the amplitude of the ERN-like response as the dependent variable. The analysis showed that erroneous responses had more negative amplitudes than correct responses $[F(1,17)=$ $\left.10.13, \mathrm{MS}_{\mathrm{e}}=14.14, p<.01\right]$. Unfortunately, we did not have sufficient trials to compare erroneous trials across conditions.

\section{Stimulus-locked Averages}

\section{Early Components}

In stimulus-locked averages, there is an apparent visual difference between distractor conditions in the N1-P2 complex. An ANOVA revealed a significant main effect of distractor relatedness $\left[F(2,34)=9.16, \mathrm{MS}_{\mathrm{e}}=14.53, p<\right.$ .001 ; see Figure 6]. More detailed analyses showed that in the CC the amplitude of $\mathrm{N} 1$ was lower than in the $\mathrm{SR}-$ and SR+ conditions $\left[F(1,17)=9.88, \mathrm{MS}_{\mathrm{e}}=31.22\right.$, $p<.01$ and $F(1,17)=11.74, \mathrm{MS}_{\mathrm{e}}=40.23, p<.01$, respectively]. Importantly, however, the difference between the SR- and the SR+ conditions was not significant $\left[F(1,17)=1.16, \mathrm{MS}_{\mathrm{e}}=15.73, n s\right]$.

Similar analyses with the latency of the N1 as dependent variable showed that the $\mathrm{N} 1$ peaked earlier during the CC than during the SR- and SR+ conditions $[F(1$, $17)=18.22, \mathrm{MS}_{\mathrm{e}}=867.61, p<.001$ and $F(1,17)=$ $22.19, \mathrm{MS}_{\mathrm{e}}=899.02, p<.001$, respectively]. Again, there was no significant difference between the SR- and SR+ conditions $[F(1,17)<1]$. These early differences between the CC and the SR+ and SR- conditions are not surprising given that auditory distractors were presented in the SR- and SR+ conditions, whereas no such distractor was present in the CC. Importantly, however, no differences were obtained between the SR+ and the SR- conditions at these early moments in the signal.

\section{N450}

In stimulus-locked averages in the time window of interest (350-550 msec), there was a significant main effect of 


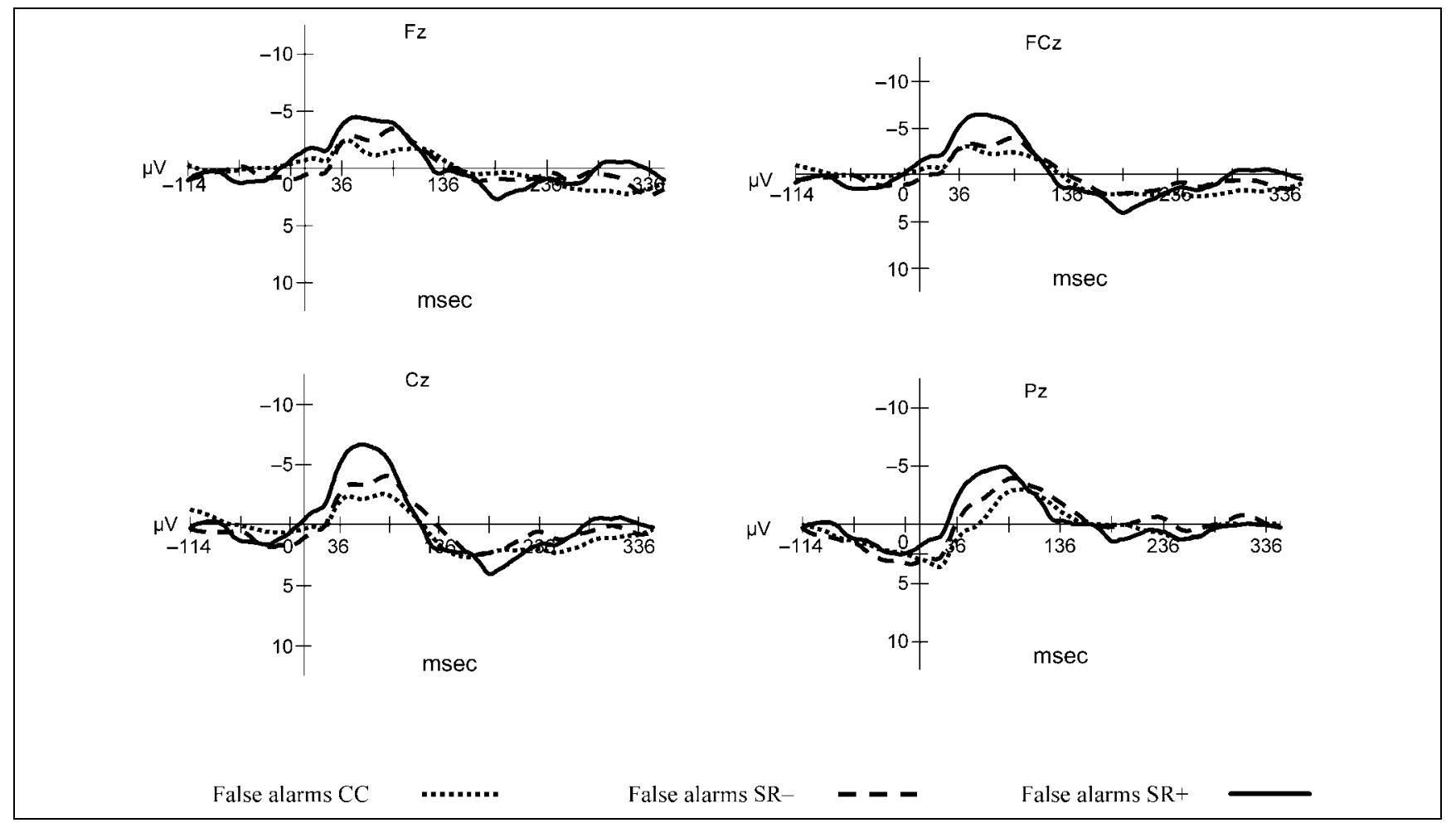

Figure 4. Averaged response-locked ERPs for false alarms (incorrect no-go trials). Dotted lines depict the control condition (CC), solid lines depict the semantically related condition ( $\mathrm{SR}+$ ), and dashed lines depict the semantically unrelated condition (SR-).

distractor relatedness $\left[F(2,34)=24.59, \mathrm{MS}_{\mathrm{e}}=3.83\right.$, $p<.001$; see Figure 6]. A higher amplitude of the N450 was visible in the $\mathrm{SR}+$ condition $(-1.30 \mu \mathrm{V}, S D=0.31)$ as compared to the SR- condition $(-1.01 \mu \mathrm{V}, S D=$ $0.29)$ and the CC $(-0.41, S D=0.29)$. These differences in the amplitude of the N450 were significant [SR+ vs.
CC: $F(1,17)=14.57, \mathrm{MS}_{\mathrm{e}}=2.41, p<.001 ; \mathrm{SR}-$ vs. CC: $F(1,17)=6.77, \mathrm{MS}_{\mathrm{e}}=1.80, p<.05 ;$ and $\mathrm{SR}+$ vs. SR-: $\left.F(1,17)=6.26, \mathrm{MS}_{\mathrm{e}}=0.95, p<.05\right]$.

To localize this effect, we ran two separate ANOVAs. First, a 3 (conditions) $\times 2$ (anterior vs. posterior position $) \times 10$ (electrode sites) ANOVA was run to investi-
Figure 5. Averaged stimulus-locked ERP waveforms for all misses (solid lines) versus correct rejections (dashed lines) collapsed across conditions Correct and incorrect trials were matched on RTs and number of trials. Areas selected by rectangles depict the time window of average button-press latencies for correct responses. Mean RTs for overt responses in go trials are provided.

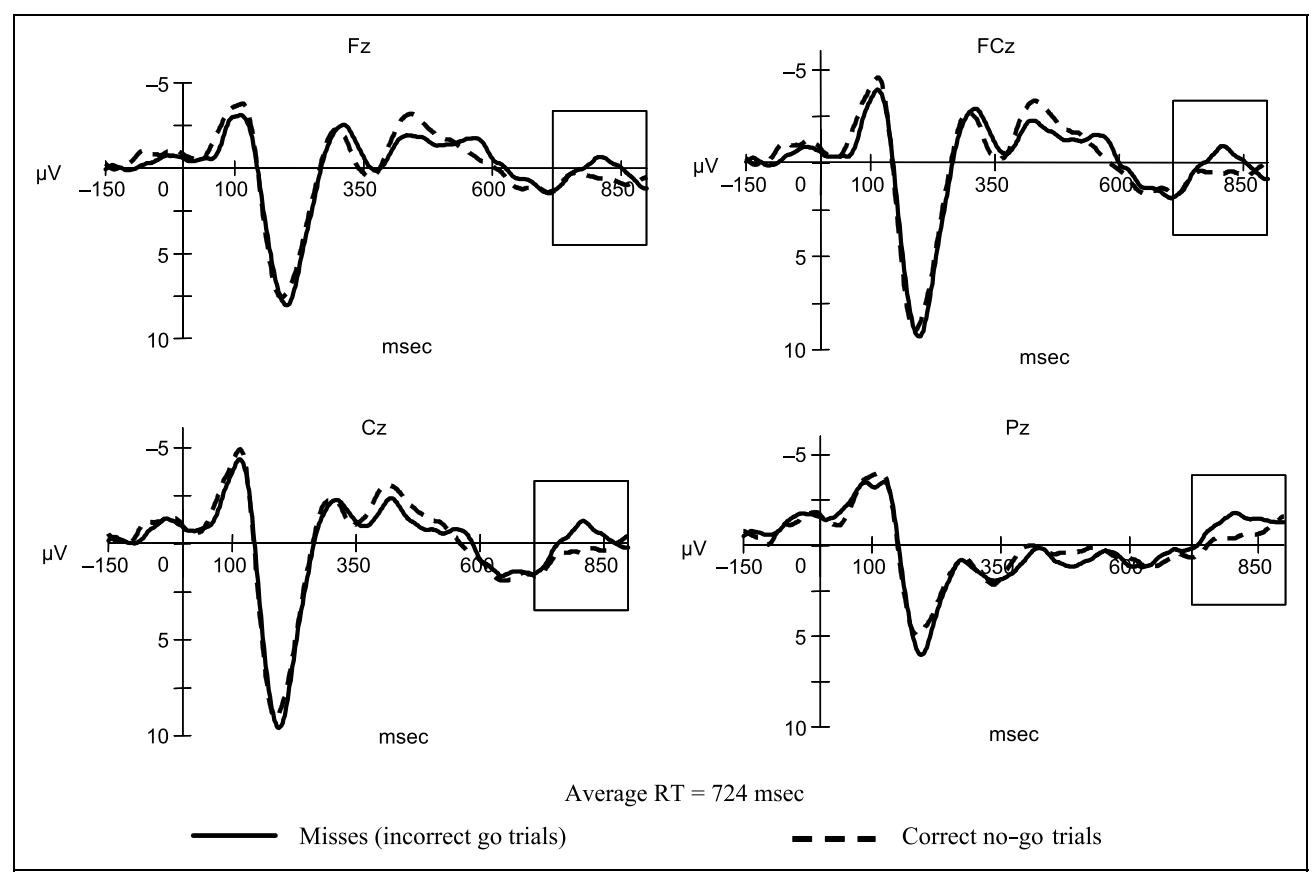


Figure 6. Grand-average ERPs time-locked to the onset of the stimulus. Dotted lines depict the control condition (CC), solid lines depict the semantically related condition $(\mathrm{SR}+)$, and dashed lines depict the semantically unrelated condition (SR-). The time window 350-550 msec that was used for statistical analysis is framed. Areas showing statistically significant differences between conditions are indicated by rectangles.

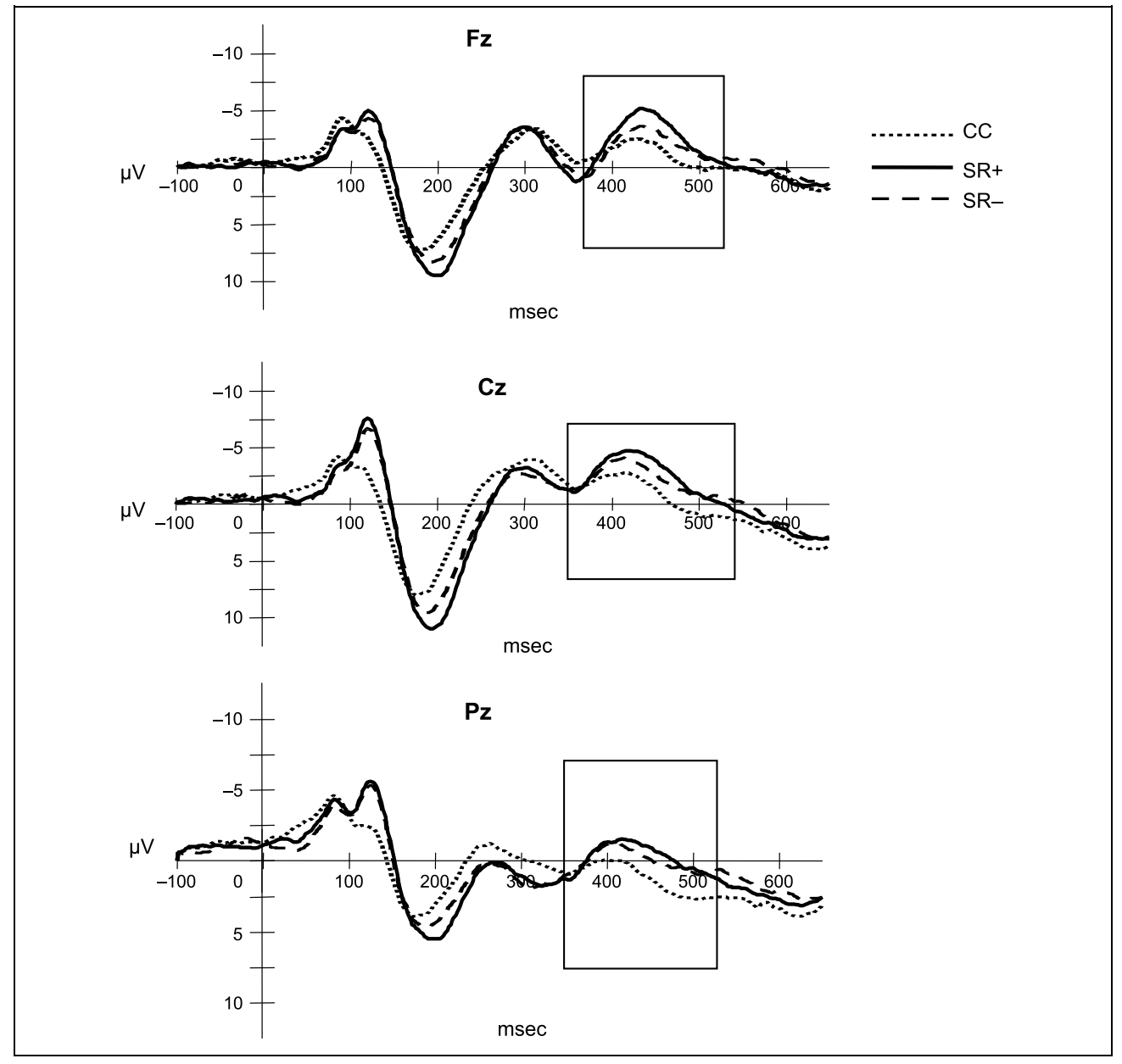

gate whether the $\mathrm{N} 450$ had a more frontal or posterior distribution. Second, a 3 (conditions) $\times 2$ (left vs right hemisphere) $\times 10$ (electrode sites) ANOVA was run to investigate whether the amplitude of the N450 was larger over the left or right hemisphere. Both of these ANOVAs revealed significant effects of position $\left[F(1,17)=15.22, \mathrm{MS}_{\mathrm{e}}=27.74, p<.01\right.$, for anterior vs. posterior; and $F(1,17)=6.45, \mathrm{MS}_{\mathrm{e}}=10.39, p<.05$, for left vs. right]. To refine this analysis, we ran a separate 3 (conditions) $\times 3$ (anterior vs. central vs. posterior position) $\times 6$ (electrode sites) ANOVA. This analysis yielded a significant effect of position $[F(2,34)=31.23$, $\left.\mathrm{MS}_{\mathrm{e}}=12.83, p<.01\right]$, with the highest amplitude of the $\mathrm{N} 450$ over anterior sites $(-1.63 \mu \mathrm{V}, S D=1.80)$, followed by central and posterior sites $(-1.06 \mu \mathrm{V}, S D=$ $1.66 ; 0.51 \mu \mathrm{V}, S D=1.33$, respectively). To be more precise, the $\mathrm{N} 450$ in our study had a left fronto-central distribution (see Figure 7).

\section{DISCUSSION}

The goal of the present study was to investigate how verbal self-monitoring is affected by auditory distractors and whether the ERN is sensitive to verbal stimulus manipulation. As expected, semantically related distractors caused a larger interference effect than unrelated distractors. Surprisingly, the presence of distractors had no influence on error rate: Participants did not commit more errors in the semantically related than in the semantically unrelated condition. However, as hypothesized, the amplitude of the ERN was significantly larger when distractors were semantically related to the target picture than when they were unrelated. Interestingly, we also demonstrated an ERN after misses, in the absence of overt motor responses (see also Ganushchak \& Schiller, 2006). During misses, participants failed to detect the target phoneme in the covertly generated picture name. It is possible that after the decision not to respond, further processing of the stimulus revealed that there actually was a target phoneme in the picture name. This, in turn, resulted in the mismatch between actual and desired response, which led to a higher conflict in the misses as compared to the correct no-go responses. Hence, an ERN was generated. Unfortunately, we did not have enough trials to investigate whether or not the ERN after misses was affected by distractor relatedness. For correct go trials, we obtained a larger negative 


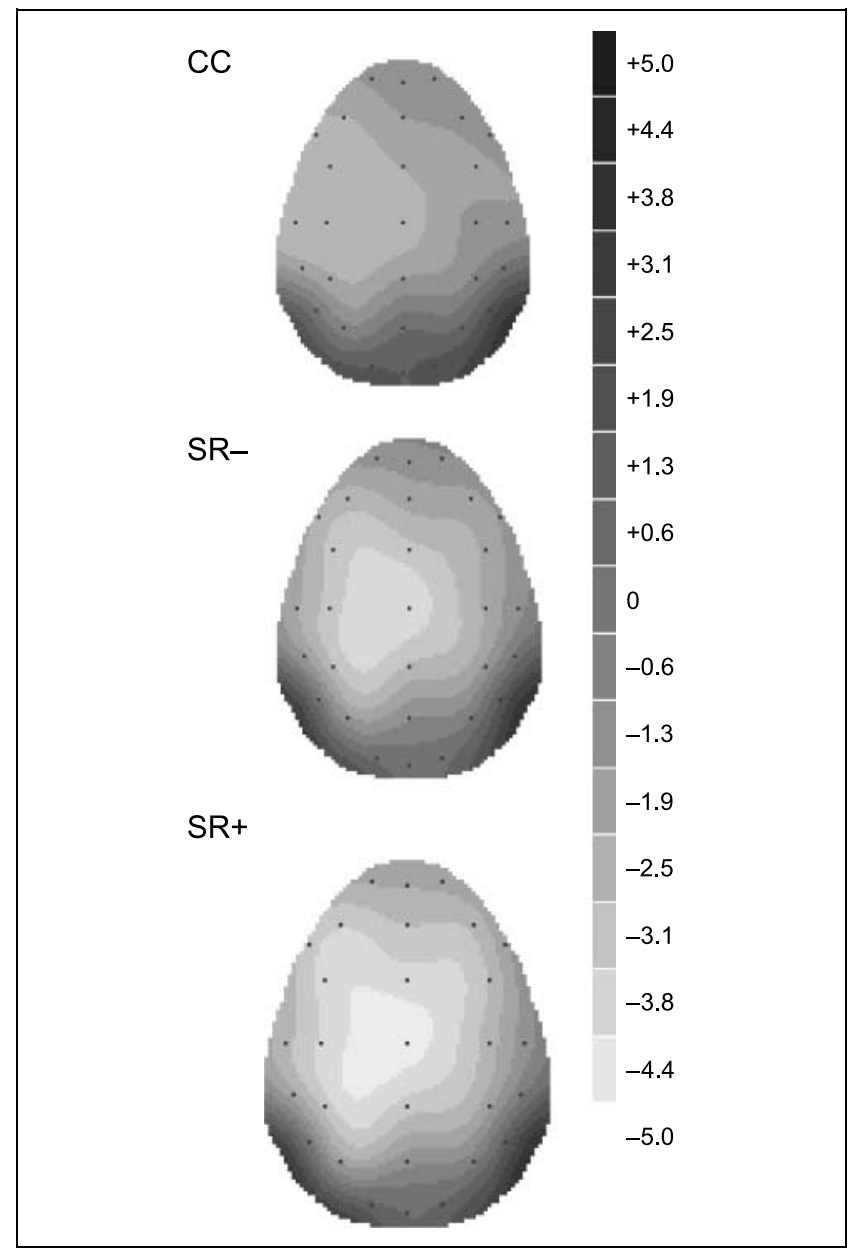

Figure 7. Topographic maps of the N450 amplitude between 400 and $500 \mathrm{msec}$ after target picture onset. Negative regions are depicted in light gray.

deflection, peaking around 450 msec after stimulus onset, for semantically related distractors than semantically unrelated ones. The N450 was smallest for the control condition, where auditory distractors were absent. These findings will be discussed in more detail below.

In accordance with a number of previous studies (e.g., Damian \& Martin, 1999; Roelofs, 1992; Schriefers et al., 1990; Glaser \& Düngelhof, 1984; Lupker, 1979), we demonstrated that semantically related auditory distractors induced an interference effect relative to semantically unrelated distractors. Semantically related distractors presumably coactivate, through the spreading of activation, multiple concepts that are semantically related to one another (Maess, Friederici, Damian, Meyers, \& Levelt, 2002). Hence, there are multiple plausible entries that are simultaneously active and compete for lexical selection (but see Mahon et al., 2007; Finkbeiner et al., 2006). The verbal self-monitor needs to verify on-line whether the correct lexical item was chosen from the pool of competing items, which in turn leads to slower responses. In the unrelated condition, however, such verification might not be as relevant because unrelated distractors do not activate related concepts, and therefore, less competition may be present at the time of the response.

Surprisingly, distractors slowed down the functioning of the monitor in our study, but did not compromise its working completely. According to the perceptual loop theory, the verbal monitor proceeds through the speech comprehension system (Levelt et al., 1999). The same system is used for processing auditory input from other speakers. Thus, in the presence of auditory distractors, the comprehension system must process auditory input and simultaneously monitor inner speech, which inevitably should lead to a higher error rate. However, in the present study, auditory distractors did not lead to more errors. Previous studies showed inconsistent changes of error rate in relation to distractors. Interestingly, it seems that studies that employed visual distractors report increases in error rate in the presence of semantically related distractors, as compared to semantically unrelated ones (e.g., Bloem, Van den Boogaard, \& La Heij, 2004; Damian \& Bowers, 2003). However, studies using auditory distractors seem to find no effect of distractor relatedness on error rate (e.g., Jescheniak, Schriefers, Garrett, \& Friederici, 2002). The fact that auditory distractors do not cause higher error rates may be due to more independence of the verbal monitor from the comprehension system than the perceptual loop theory presumes. This possibility is also implied by research on aphasic patients demonstrating a double dissociation between the comprehension and the monitoring system (e.g., intact comprehension but impaired monitoring or vice versa). For example, Marshall, Robson, Pring, and Chiat (1998) described patients with jargon aphasia who failed to detect their neologisms despite their relatively preserved comprehension, whereas Marshall, Rappaport, and Garcia-Bunuel (1985) reported aphasic patients with severely impaired auditory comprehension who, nevertheless, exhibited well-preserved self-monitoring skills.

Our behavioral results are supported by the EEG data. First, in stimulus-locked averages, we found that the amplitude of the $\mathrm{N} 450$ was modulated by the relatedness of distractors. Semantically related distractors led to higher N450 amplitudes than semantically unrelated distractors. In previous studies, the N450 was associated with the amount of conflict; the larger the conflict, the larger the amplitude of the N450 (West \& Alain, 1999). In the present study, semantically related distractors presumably increased conflict by activating multiple concepts, thus increasing the amplitude of the N450. Second, we showed that the amplitude of the response-locked ERN was also contingent on the relatedness of distractors. The amplitude of the ERN was smallest when distractors were absent and largest when distractors were semantically related to the target picture. In the present study, the semantically unrelated distractors did not lead to a significant increase of the amplitude of the ERN, as compared 
to the control condition. It might be that semantically unrelated distractors did not elicit enough conflict to be detected by changes in the ERN. It is also possible, however, that this difference would become significant at a higher error rate than in the present study.

The ERN has been associated with the amount of conflict between plausible responses (Botvinick et al., 2001). Our data are in accordance with this assumption. As mentioned above, semantically related distractors activate multiple concepts that are related to the target, thereby leading to greater competition between them. Hence, in the semantically related condition at the time of a response, there may be more conflict between competing responses than in the semantically unrelated condition or in the absence of distractor words, thereby leading to a larger ERN amplitude. Due to the simultaneous activation of competing lexical items, the verbal self-monitor presumably needs to be more alert during the semantically related condition than during unrelated and control conditions in order to validate whether the given response was correct or erroneous.

The design of the present experiment makes it difficult to disentangle if the increased amplitude of the ERN was due to increased response conflict or other factors (e.g., awareness of errors). The presence of the semantically related distractors presumably increases conflict at the level of lexical retrieval but does not necessarily lead to response conflict. We argued that the semantically related distractors activate multiple lexical entries, which in turn lead to multiple potential responses active at the same time and therefore, albeit indirectly, lead to higher response conflict. However, we cannot exclude the possibility that there was only lexical conflict present. Interestingly, West et al. (2004) demonstrated that the ACC as well as N450 are sensitive not only to response conflict, as generally accepted, but also to nonresponse conflict (i.e., conflict that arises prior to response processing, e.g., at phonetic and/or semantic levels). The dipole model used to fit the neural generators of the N450 was similar to that used to fit the ERN. These findings suggest that the ERN might be sensitive not only to response conflict but also to nonresponse conflict. In light of these findings, it is possible that response conflict is not a necessary condition to elicit the ERN, and that the increase in amplitude of the ERN found in the present study could have been due to the increase of lexical conflict.

Alternatively, previous research showed that the ERN can be modulated by the perceived awareness of errors (e.g., Scheffers \& Coles, 2000; for alternative views, see O'Connell et al., 2007; Nieuwenhuis, Ridderinkhof, Blom, Band, \& Kok, 2001). In the present study, one may argue that the difference in ERN amplitude between conditions was due to differences in awareness of the errors that were made. For example, participants could have been more aware of their errors in the semantically related condition than in semantically unrelated and control conditions, thereby causing higher ERN amplitudes. However, the subjective confidence data, collected in the present study, showed that participants were equally aware of their errors in all experimental conditions. Therefore, we conclude that the increase in ERN amplitude during the semantically related condition was most likely due to the simultaneous activation of competing lexical items and not because participants could more easily recognize their errors in the semantically related than in the semantically unrelated condition.

To conclude, there is increasing evidence that verbal errors are similar to action errors of a more general performance monitor. As stated above, in the current study, we showed that the ERN is sensitive to the presence of lexical conflict. Similarly, in previous studies (i.e., Ganushchak \& Schiller, 2006), we reported a typical decrease of the ERN amplitude after errors of verbal monitoring under conditions of time pressure. Furthermore, Möller et al. (2007)—employing the inverse source localization method-identified a medial frontal generator in the supplementary motor area (SMA) as the main source of the negativity preceding erroneous vocalizations. A typical ERN has been located within the ACC/ SMA regions (e.g., Dehaene, Posner, \& Tucker, 1994). Based on these findings, we suggest here that the verbal monitor works in a similar way as a general performance monitor. It is possible that, during verbal monitoring and during executive action monitoring, a copy of the on-line response is created and compared to the representation of the correct response (see Levelt et al., 1999). If there is a mismatch between them, an error signal is generated and corrective processes can be startedsimilar to action monitoring (see Rodrígues-Fornells et al., 2002; Desmurget \& Grafton, 2000). We would like to propose here that verbal monitoring might be a special case of general performance monitoring instead of a completely separate process.

In summary, we showed that the ERN can successfully be elicited by errors of verbal monitoring and is sensitive to verbal stimulus manipulations. This provides further proof that the ERN could be used as an electrophysiological marker of error processing in language research. However, in the present study, the required responses were button presses. We believe that the majority of errors observed in the current study were errors of the verbal monitor and based on the incorrect decision about the target phoneme (as demonstrated by the ERN-like responses on misses). However, we cannot completely rule out the possibility that some of the errors could have been due to action slips and not slips of verbal monitoring per se. Therefore, more research is needed to be able to make a clearer dissociation between errors of verbal and other action monitoring. 


\section{APPENDIX}

List of stimuli used in the experiment

\begin{tabular}{|c|c|c|c|c|}
\hline \multirow[b]{3}{*}{ Pictures } & \multicolumn{4}{|c|}{ Distractors } \\
\hline & \multicolumn{2}{|c|}{ Go Trials } & \multicolumn{2}{|c|}{ No-go Trials } \\
\hline & Semantically Related & Semantically Unrelated & Semantically Related & Semantically Unrelated \\
\hline baard ("beard") & wenkbrauw ("brow") & wagen (“wagon") & sik ("goatee") & wok ("wok") \\
\hline bloem ("flower") & kruid (“herb”) & veer (“ferry”) & plant ("plant") & bus ("bus") \\
\hline broek ("trousers") & vest ("waistcoat") & stal ("stable") & trui ("sweater") & kruid ("herb”) \\
\hline fiets ("bicycle") & brommer ("moped") & medaillon ("medallion") & step (“scooter") & tap ("tap") \\
\hline film ("film") & dia ("slide") & sik ("goatee") & rol ("spool") & lip (“lip”) \\
\hline fles ("bottle") & kan ("pitcher") & fee ("fairy") & glas ("glass") & oor ("ear") \\
\hline heks ("witch") & elf (“elf”) & berg ("mountain") & fee ("fairy") & hes ("smock") \\
\hline hemd ("shirt") & rok ("skirt") & wang (“cheek”) & shirt ("shirt") & schors ("bark") \\
\hline hoorn (“horn”) & fluit ("flute") & muts ("bonnet") & viool ("violin") & kruik (“jar”) \\
\hline jurk (“dress") & bloes ("blouse") & been ("leg") & kous ("stocking") & beurs ("fair") \\
\hline kaart ("card") & fiche ("token") & bazaar ("bazar") & roulette ("roulette") & collier ("necklace") \\
\hline kaas ("cheese") & paté ("paté") & metro ("metro") & ham ("ham") & hol (“den”) \\
\hline kar (“cart”) & slee ("sled”) & muil (“slipper”) & wagen ("wagon") & wenkbrauw ("brow") \\
\hline knie ("knee”) & voet ("foot") & rol ("spool”) & been (“leg") & bank (“couch") \\
\hline kraan ("faucet") & tap ("tap") & step (“scooter") & douche ("shower") & fiche ("token") \\
\hline kroon ("crown") & scepter (“scepter”) & roulette ("roulette") & baret ("beret") & kano ("canoe") \\
\hline maan ("moon") & heelal ("cosmos") & douche ("shower") & hemel (“sky”) & vinger ("finger") \\
\hline markt ("market") & beurs ("fair") & viool (“violin”) & bazaar ("bazaar") & gondel ("gondola") \\
\hline mes ("knife") & lepel (“spoon”) & ladder ("ladder") & vork ("fork") & haas ("hare") \\
\hline muur (“wall”) & dak ("roof") & plant ("plant") & raam ("window") & voet ("foot") \\
\hline nest ("nest") & hol ("den") & trui ("sweater") & stal ("stable") & rok ("skirt") \\
\hline neus ("nose") & oor ("ear") & raam ("window") & wang (“cheek") & bloes ("blouse") \\
\hline pan ("pan") & wok ("wok") & das ("badger") & schotel (“dish”) & scepter (“scepter") \\
\hline pet ("cap") & hes ("smock") & huig ("uvula") & muts ("bonnet") & fluit ("flute") \\
\hline plank ("board") & staaf ("rod") & kous (“stocking") & balk ("beam”) & sjaal (“scarf”) \\
\hline pot ("pot") & kruik (“jar”) & kruk ("stool”) & vaas ("vase") & staaf ("rod") \\
\hline riem ("belt") & sjaal ("scarf”) & vaas ("vase") & das ("badger") & dia ("slide") \\
\hline ring ("ring") & collier ("necklace") & schotel (“dish") & medaillon ("medallion") & brommer ("moped") \\
\hline rots ("cliff") & leem ("loam”) & ham ("ham") & berg ("mountain”) & elf ("elf”) \\
\hline schip (“ship”) & kano ("canoe") & baret ("beret") & boot ("boat") & kaak (“jaw”) \\
\hline schoen ("shoe") & klomp (“clog”) & balk (“beam”) & muil (“slipper”) & slee ("sled") \\
\hline slang ("snake") & haas ("hare") & vork ("fork") & hagedis ("lizard") & heelal (“cosmos") \\
\hline snor ("mustache") & kaak (“jaw”) & stam ("trunk") & haar ("hare") & dak ("roof") \\
\hline tak ("branch") & schors ("bark") & shirt ("shirt") & stam ("trunk") & vest ("waistcoat") \\
\hline tong ("tong") & lip (“lip”) & haar ("hair") & huig ("uvula") & leem (“loam”) \\
\hline tram ("tram") & gondel ("cable car") & hagedis ("lizard") & veer ("ferry") & klomp (“clog”) \\
\hline trap ("stairs") & lift ("lift") & boot ("boat") & ladder ("ladder") & lepel (“spoon”) \\
\hline trein ("train") & bus ("bus") & duim ("thumb") & metro ("metro") & pate ("pate") \\
\hline troon ("throne") & bank (“couch”) & glas ("glass") & kruk ("stool”) & kan (“pitcher”) \\
\hline vuist (“fist”) & vinger ("finger") & hemel (“sky") & duim ("thumb") & lift ("lift") \\
\hline
\end{tabular}




\section{Acknowledgments}

The work presented in this article was supported by NWO grant 453-02-006 to Niels O. Schiller. We thank three anonymous reviewers for helpful comments on earlier versions of this manuscript. The article benefited from discussions following presentations at the Psycholinguistics in Flanders workshop in Leuven (Belgium), May 2005; the Endo-Neuro-Psycho meeting in Doorwerth (The Netherlands), June 2005; the Second International Workshop on Language Production in Maastricht (The Netherlands), August, 2005; the annual meeting of the Belgian Association for Psychological Science in Liège (Belgium), May 2006; and the Errors, Conflicts, and Rewards workshop in Amsterdam (The Netherlands), June 2006.

Reprint requests should be sent to Lesya Y. Ganushchak, Department of Cognitive Psychology, Leiden University-Institute for Psychological Research (LU-IPR), Wassenaarseweg 52, 2333 AK Leiden, The Netherlands, or via e-mail: lganushchak@fsw. leidenuniv.nl.

\section{REFERENCES}

Anderer, P., Safety, B., Kinsperger, K., \& Semlitsch, H. (1987). Topographic brain mapping of EEG in neuropsychopharmacology-Part 1. Methodological aspects. Methods and Findings in Experimental Clinical Pharmacology, 9, 371-384.

Baayen, R. H., Piepenbrock, R., \& Gulikers, L. (1995). The CELEX lexical database (CD-ROM), Linguistic Data Consortium, University of Pennsylvania, Philadelphia, PA.

Bernstein, P. S., Scheffers, M. K., \& Coles, M. G. H. (1995). "Where did I go wrong?" A psychophysiological analysis of error detection. Journal of Experimental Psychology: Human Perception and Performance, 21, 1312-1322.

Bloem, I., Van den Boogaard, S., \& La Heij, W. (2004). Semantic facilitation and semantic interference in language production: Further evidence for the conceptual selection model of lexical access. Journal of Memory and Language, 51, 307-323.

Botvinick, M. M., Braver, T. S., Barch, D. M., Carter, C. S., \& Cohen, J. D. (2001). Conflict monitoring and cognitive control. Psychological Review, 108, 624-652.

Carter, C. S., Braver, T. S., Barch, D. M., Botvinick, M. M., Noll, D. C., \& Cohen, J. D. (1998). Anterior cingulated cortex, error detection, and the online monitoring of performance. Science, 280, 747-749.

Coles, M. G. H., Scheffers, M. K., \& Holroyd, C. B. (2001). Why is there an ERN/Ne on correct trials? Response representations, stimulus-related components, and the theory of error-processing. Biological Psychology, 56, 173-189.

Collins, A. M., \& Loftus, E. F. (1975). A spreading-activation theory of semantic processing. Psychological Review, 82, 407-428.

Damian, M. F., \& Bowers, J. S. (2003). Locus of semantic interference in picture-word interference tasks. Psychonomic Bulletin and Review, 10, 111-117.

Damian, M. F., \& Martin, R. C. (1999). Semantic and phonological codes interact in single word production. Journal of Experimental Psychology: Learning, Memory, and Cognition, 25, 345-361.

Dehaene, S., Posner, M. I., \& Tucker, D. M. (1994). Localization of a neural system for error detection and compensation. Psychological Science, 5, 3-23.

Desmurget, M., \& Grafton, S. T. (2000). Forward modeling allows feedback control for fast reaching movements. Trends in Cognitive Sciences, 4, 423-431.
Falkenstein, M., Hohnsbein, J., Hoorman, J., \& Blanke, L. (1991). Effects of crossmodal divided attention on late ERP components: II. Error processing in choice reaction tasks. Electroencephalography and Clinical Neurophysiology, 78, 447-455.

Falkenstein, M., Hoormann, J., Christ, S., \& Hohnsbein, J. (2000). ERP components on reaction errors and their functional significance: A tutorial. Biological Psychology, 51, 87-107.

Finkbeiner, M., Gollan, T. H., \& Caramazza, A. (2006). Lexical access in bilingual speakers: What's the (hard) problem? Bilingualism: Language and Cognition, 9, 153-166.

Ganushchak, L. Y., \& Schiller, N. O. (2006). Effects of time pressure on verbal self-monitoring. Brain Research, 1125, 104-115.

Gehring, W. J., Goss, B., Coles, M. G. H., Meyer, D. E., \& Donchin, E. (1993). A neural system for error detection and compensation. Psychological Science, 4, 385-390.

Glaser, W. R., \& Düngelhof, F. J. (1984). The time course of picture-interference. Journal of Experimental Psychology: Human Perception and Performance, 10, 640-654.

Holroyd, C. B., \& Coles, M. G. H. (2002). The neural basis of human error processing: Reinforcement learning, dopamine and the error-related-negativity. Psychological Review, 109, 679-709.

Holroyd, C. B., \& Yeung, N. (2003). Alcohol and error processing. Trends in Neurosciences, 26, 402-404.

Jescheniak, J., Schriefers, H., Garrett, M. F., \& Friederici, A. D. (2002). Exploring the activation of semantic and phonological codes during speech planning with event-related brain potentials. Journal of Cognitive Neuroscience, 14, 951-964.

Levelt, W. J. M. (1983). Monitoring and self-repair in speech. Cognition, 14, 41-104.

Levelt, W. J. M. (1989). Speaking: From intention to articulation. Cambridge: MIT Press.

Levelt, W. J. M., Roelofs, A., \& Meyer, A. S. (1999). A theory of lexical access in speech production. Behavioral and Brain Sciences, 22, 1-75.

Lickley, R. J., Hartsuiker, R. J., Corley, M., Russell, M., \& Nelson, R. (2005). Judgment of disfluency in people who stutter and people who do not stutter: Results from magnitude estimation. Language and Speech, 48, 299-312.

Liotti, M., Woldorff, M. G., Perez, R., III, \& Mayberg, H. S. (2000). An ERP study of the temporal course of the Stroop color-word interference effect. Neuropsychologia, 38, 701-711.

Lupker, S. J. (1979). The semantic nature of response competition in the picture-word interference task. Memory \& Cognition, 7, 485-495.

Maess, B., Friederici, A. D., Damian, M., Meyers, A. S., \& Levelt, W. J. M. (2002). Semantic category interference in overt picture naming: Sharpening current density localization by PCA. Journal of Cognitive Neuroscience, 14, 455-462.

Mahon, B. Z., Costa, A., Peterson, R., Vargas, K. A., \& Caramazza, A. (2007). Lexical selection is not by competition: A reinterpretation of semantic interference and facilitation effects in the picture-word interference paradigm. Journal of Experimental Psychology: Learning, Memory, and Cognition, 33, 503-535.

Marshall, J., Robson, J., Pring, T., \& Chiat, S. (1998). Why does monitoring fail in jargon aphasia? Comprehension, judgment, and therapy evidence. Brain and Language, 63, 79-107.

Marshall, R. C., Rappaport, B. Z., \& Garcia-Bunuel, L. (1985). Self-monitoring behavior in a case of severe auditory agnosia with aphasia. Brain and Language, 24, 297-313. 
Masaki, H., Tanaka, H., Takasawa, N., \& Yamazaki, K. (2001). Error-related brain potentials elicited by vocal errors. NeuroReport, 12, 1851-1855.

Möller, J., Jansma, B. M., Rodríguez-Fornells, A., \& Münte, T. F. (2007). What the brain does before the tongue slips. Cerebral Cortex, 17, 1173-1178.

Morgan, L. J., \& Wheeldon, L. R. (2003). Syllable monitoring in internally and externally generated English words. Journal of Psycholinguistic Research, 32, 269-296.

Motley, M. T., Camden, C. T., \& Baars, B. J. (1982). Covert formulation and editing of anomalies in speech production: Evidence from experimentally elicited slips of the tongue. Journal of Verbal Learning and Verbal Behavior, 21, 578-594.

Nieuwenhuis, S., Ridderinkhof, K. R., Blom, J., Band, G. P. H., \& Kok, A. (2001). Error-related brain potentials are differentially related to awareness of response errors: Evidence from an antisaccade task. Psychophysiology, 38, 752-760.

O'Connell, R. G., Dockree, P. M., Bellgrove, M. A., Kelly, S. P., Hester, R., Garavan, H., et al. (2007). The role of cingulate cortex in the detection of errors with and without awareness: A high-density electrical mapping study. European Journal of Neuroscience, 25, 2571-2579.

Oomen, C. C. E., Postma, A., \& Kolk, H. (2001). Prearticulatory and postarticulatory self-monitoring in Broca's aphasia. Cortex, 37, 627-641.

Postma, A. (2000). Detection of errors during speech production: A review of speech monitoring models. Cognition, 77, 97-131.

Postma, A., \& Noordanus, C. (1996). Production and detection of speech errors in silent, mouthed, noise-masked, and normal auditory feedback speech. Language and Speech, 39, 375-392.

Quillian, M. R. (1968). Semantic memory. In M. Minsky (Ed.), Semantic information processing (pp. 227-270). Cambridge: MIT Press.

Rodrígues-Fornells, A., Kurzbuch, A. R., \& Münte, T. F. (2002). Time course of error detection and correction in humans: Neurophysiological evidence. Journal of Neuroscience, 22, 9990-9996.

Roelofs, A. (1992). A spreading-activation theory of lemma retrieval in speaking. Cognition, 42, 107-142.

Scheffers, M. K., \& Coles, M. G. H. (2000). Performance monitoring in a confusing world: Error-related brain activity, judgments of response accuracy, and types of errors. Journal of Experimental Psychology, 26, $141-151$.

Scheffers, M. K., Coles, M. G. H., Bernstein, P. S., Gehring, W. J., \& Donchin, E. (1996). Event-related brain potential and error-related processing: An analysis of incorrect responses to go and no-go stimuli. Psychophysiology, 33, 42-53.

Schiller, N. O. (2005). Verbal self-monitoring. In A. Cutler (Ed.), Twenty-first century psycholinguistics: Four cornerstones (pp. 245-261). Mahwah, NJ: Erlbaum.

Schiller, N. O. (2006). Lexical stress encoding in single word production estimated by event-related brain potentials. Brain Research, 1112, 201-212.

Schiller, N. O., Jansma, B. M., Peters, J., \& Levelt, W. J. M. (2006). Monitoring metrical stress in polysyllabic words. Language and Cognitive Processes, 21, 112-140.

Schriefers, H., Meyer, A. S., \& Levelt, W. J. M. (1990). Exploring the time course of lexical access in language production: Picture-word interference studies. Journal of Memory and Language, 26, 86-102.

Seal, M. L., Aleman, A., \& McGuire, P. K. (2004). Compelling imagery, unanticipated speech and deceptive memory: Neurocognitive models of auditory verbal hallucinations in schizophrenia. Cognitive Neuropsychiatry, 9, 43-72.

Sebastián-Gallés, N., Rodríguez-Fornells, A., De Diego-Balaquer, R., \& Díaz, B. (2006). First- and second-language phonological representation in the mental lexicon. Journal of Cognitive Neuroscience, 18, 1277-1291.

Starreveld, P. A., \& La Heij, W. (1995). Semantic interference, orthographic facilitation, and their interaction in naming tasks. Journal of Experimental Psychology: Learning, Memory, and Cognition, 21, 686-698.

Starreveld, P. A., \& La Heij, W. (1996). Time-course analysis of semantic and orthographic context effects in picture naming. Journal of Experimental Psychology: Learning, Memory, and Cognition, 22, 896-918.

West, R. (2003). Neural correlates of cognitive control and conflict detection in the Stroop and digit-location tasks. Neuropsychologia, 41, 1122-1135.

West, R., \& Alain, C. (1999). Event-related neural activity associated with the Stroop task. Cognitive Brain Research, 8, 157-164.

West, R., Bowry, R., \& McConville, C. (2004). Sensitivity of medial frontal cortex to response and nonresponse conflict. Psychophysiology, 41, 739-748.

Wheeldon, L. R., \& Levelt, W. J. M. (1995). Monitoring the time course of phonological encoding. Journal of Memory and Language, 34, 311-334.

Wheeldon, L. R., \& Morgan, J. L. (2002). Phoneme monitoring in internal and external speech. Language and Cognitive Processes, 17, 503-535.

Yeung, N., Botvinick, M. M., \& Cohen, J. D. (2004). The neural basis of error detection: Conflict monitoring and the error-related negativity. Psychological Review, 111, 931-959. 